\title{
Synthesis of Soluble Novel Polyacetylenes Containing Carbamate and Eugenol Moieties
}

\author{
Erwin Abdul Rahim
}

Department of Chemistry, Tadulako University, Jl. Sukarno-Hatta Km 9, Palu 94148, Central Sulawesi, Indonesia

*Corresponding author:

email:erwin_abdulrahim@yahoo.com

Received: May 4, 2019

Accepted: September 24, 2019

DOI: $10.22146 / \mathrm{ijc} .45603$

\begin{abstract}
This study was aimed to synthesize a series of novel polyacetylenes containing carbamate and eugenol moieties. The polymerization of 1-(3,4-dimethoxyphenyl) propane-2-yl prop-2-ynylcarbamate (1), 1-(3,4-dimethoxyphenyl)propane-2-yl 3-ethynyl phenylcarbamate (2), 1-(3,4-dimethoxyphenyl)propane-2-yl 4-ethynylphenylcarbamate (3), (2S)-1-(3,4-dimethoxyphenyl)propane-2-yl 2-((prop-2ynyloxy)carbonylamino)propanoate (4) in the presence of $(n b d) R h^{+}\left[n 6-C_{6} H_{5} B^{-}\left(C_{6} H_{5}\right)_{3}\right]$ as catalyst have successfully produced corresponding polyacetylenes [poly(1)-poly(4)] in high yield. The molecular weight of the synthesized polyacetylenes ranged between 13,900-18,400 $\mathrm{g} / \mathrm{mol}$. In particular, the molecular weight of poly(1) could be increased by the addition of menthol. Practically, these polymers were found to have a stable helical structure and soluble in common organic solvents.
\end{abstract}

Keywords: polyacetylenes; carbamate; eugenol; Rh catalyst; helical structure

\section{- INTRODUCTION}

Eugenol (4-allyl-2-methoxyphenol) has been recognized to approximately covering $80-90 \%$ of the clove oil weight. In fact, it is primarily produced and continued to grow in Indonesia [1-2]. In general, the eugenol compound has the molecular formula of $\mathrm{C}_{10} \mathrm{H}_{12} \mathrm{O}_{2}$, which contains several functional groups, including allyl $\left(-\mathrm{CH}_{2}-\right.$ $\left.\mathrm{CH}=\mathrm{CH}_{2}\right)$, phenol $(-\mathrm{OH})$, and methoxy $\left(-\mathrm{OCH}_{3}\right)$. Those functional groups allow eugenol to be used as a raw material for the synthesis of other more valuable compounds. For instance, Miao et al. [3] have utilized eugenol as a bio-based heat-resistant epoxy resin. Deng et al. [4] have utilized eugenol as polymeric oil-absorbent microspheres. Meanwhile, Liu et al. [5] have applied eugenol as a bio-renewable thermosetting copolymer.

On the other hand, the helical polyacetylenes have been attracting interests due to their unique structure, chiroptical properties and potentials for being utilized in various critical applications, including as a stimuliresponsive chiral material, enantioselective catalysts, a chemical sensor, chiral discrimination, and optical crystalline material [6]. In poly( $\mathrm{N}$-propargylamides) and poly( $N$-propargyl carbamates), the amide groups could stabilize the helical structure by an intramolecular hydrogen bond as well as steric repulsion between their side chain(s) [7]. In other words, a combination of the steric repulsion and the strengthened intramolecular hydrogen bond will result in a far more stable helical structure.

A recent study demonstrated that $\operatorname{poly}(N$ propargyl carbamates) containing eugenol scaffold has been successfully synthesized by using (nbd) $\mathrm{Rh}^{+}\left[\eta 6^{-}\right.$ $\left.\mathrm{C}_{6} \mathrm{H}_{5} \mathrm{~B}^{-}\left(\mathrm{C}_{6} \mathrm{H}_{5}\right)_{3}\right]$ catalyst. In fact, the monomer is known to have a splitting methoxy group, where the corresponding polymer would have a moderate molecular weight. If recrystallization is conducted on the monomer until its methoxy group is not splitting anymore, molecular weight $\left(M_{\mathrm{n}}\right)$ and polydispersity index (PDI) of the monomer will significantly increase. The polymer can function as a smart material [8]. On the other hand, there is another possibility to increase the molecular weight and PDI of a novel derived eugenol having the methoxy group splitting. Shiotsuki et al. [9] revealed that the chiroptical properties of the amino acid based polyacetylenes strongly depend on their molecular weight. Therefore, this study was aimed to prepare novel polymers by introducing eugenol moiety to $\operatorname{poly}(N$ propargyl carbamates) and phenylacetylene, which contain carbamate group. In general, this article reports the synthesis and characterization of novel polymers 
from derived from eugenol, as a starting material, by utilizing (nbd) $\mathrm{Rh}^{+}\left[\eta 6-\mathrm{C}_{6} \mathrm{H}_{5} \mathrm{~B}^{-}\left(\mathrm{C}_{6} \mathrm{H}_{5}\right)_{3}\right]$ as an effective catalyst in the polymerization of monosubstituted acetylene.

\section{- EXPERIMENTAL SECTION}

\section{Materials}

Methyleugenol (4-allyl-2-methoxyphenyl) was provided by Indesso Co., Ltd. 1-(3,4-Dimethoxyphenyl)propane-2-ol was prepared by reacting methyl eugenol with formic acid, which would then be hydrolyzed with potassium hydroxide [10]. Besides, (nbd) $\mathrm{Rh}^{+}\left[\eta^{6}-\mathrm{C}_{6} \mathrm{H}_{5} \mathrm{~B}^{-}\right.$ $\left.\left(\mathrm{C}_{6} \mathrm{H}_{5}\right)_{3}\right]$ was prepared by reacting $[(\mathrm{nbd}) \mathrm{RhCl}]_{2}$ with $\mathrm{NaB}\left(\mathrm{C}_{6} \mathrm{H}_{5}\right)_{4}$ [11]. While [(nbd) $\left.\mathrm{RhCl}\right]_{2}$ was provided by Aldrich, other reagents were commercially provided by Wako Pure Chemical Industries. In this study, tetrahydrofuran (THF) used for polymerization was purified by applying a standard purification procedure.

\section{Instrumentation}

The ${ }^{1} \mathrm{H}$ and ${ }^{13} \mathrm{C}$ NMR spectra were recorded in chloroform-d $\left(\mathrm{CDCl}_{3}\right)$ on a JEOL EX-400 spectrometer. The IR spectra, on the other hand, were measured by applying a Shimadzu FTIR-8100 spectrophotometer. Furthermore, the melting points were determined with a Yanaco micro melting point apparatus. Carlo Erba 1106 was applied in this study as an elemental analyzer, while Jasco J-810 spectropolarimeter was used to record Circular Dichroism (CD) spectra. The specific rotation $[\alpha]_{D}$ values were measured on a Jasco DIP-1000 digital polarimeter with a sodium lamp as the light source. The numberaverage molecular weight $\left(M_{\mathrm{n}}\right)$ and weight-average molecular weight $\left(M_{\mathrm{w}}\right)$ were estimated by using gel permeation chromatography (GPC) with Shodex K804, K805, and K806 columns eluted with THF as an eluent, polystyrene calibration, refractive-index, and UV detectors.

\section{Procedure}

\section{Synthesis of monomers}

1-(3,4-Dimethoxyphenyl)propane-2-yl prop-2-ynyl carbamate (1). First, 1-(3,4-dimethoxyphenyl)-propane2-ol (19.6 g, $0.1 \mathrm{~mol}, 1$ equiv.) was added to a solution of tryphosgene ( $25 \mathrm{~g}, 0.1 \mathrm{~mol} 1$ equiv.) in dry ether $(200 \mathrm{~mL})$ at $0{ }^{\circ} \mathrm{C}$, and the resulting mixture was stirred at the same temperature for $1 \mathrm{~h}$. Next, propargylamide $(7.97 \mathrm{~g}, 0.1 \mathrm{~mol}$,
1 equiv.) was added to the mixture, and the mixture was continuously stirred at $0{ }^{\circ} \mathrm{C}$ overnight. After that, a white precipitate was filtered off, and the filtrate was concentrated. Ethyl acetate $(100 \mathrm{~mL})$ was later added to the residue. The organic phase was washed with $2 \mathrm{M} \mathrm{HCl}$, saturated with aqueous $\mathrm{NaHCO}_{3}$, dried over $\mathrm{MgSO}_{4}$, and then concentrated. In the end, monomer 1 was isolated and purified by applying column chromatography with silica gel as solid adsorbent, which was then eluted by using $3 / 2(\mathrm{v} / \mathrm{v}) n$-hexane/ethyl acetate to form a white solid. Yield: $25 \%$ : $\mathrm{mp} 90-93^{\circ} \mathrm{C} ;[\alpha]_{\mathrm{D} 20}=0^{\circ}(c=0.1 \mathrm{~g} / \mathrm{dL}$ in $\mathrm{CDCl} 3) .{ }^{1} \mathrm{H}$ NMR (400 MHz, $\left.\mathrm{CDCl}_{3}, \delta\right): 1.21-1.37$ (m, $\left.3 \mathrm{H}, \mathrm{CH}_{3}\right), 2.22(\mathrm{~s}, 1 \mathrm{H} ; \equiv \mathrm{CH}), 2.53-2.89(\mathrm{~d}, J=3.4 \mathrm{~Hz}$, $\left.2 \mathrm{H},-\mathrm{CH}_{2}-\mathrm{Ar}\right), 3.86\left(\mathrm{~d}, J=3.4 \mathrm{~Hz}, \mathrm{OCH}_{3}\right), 4.17(\mathrm{~s}, 1 \mathrm{H},-$ NHCO-), 4.98-5.02 (m, 2H, -CH-), 6.23 (s, 1H, - $\mathrm{CH}_{2-}$ $\mathrm{NH}-)$, 6.71-6.80 (m, 3H, Ar); ${ }^{13} \mathrm{C}$ NMR (400 MHz, $\left.\mathrm{CDCl}_{3}, \delta\right): 17.1,19.0,32.8,42.3,53.1,56.3,68.3,71.6$, 80.4, 114.9, 115.2, 121.6, 144.9, 147.7, 132.1, 157.5, 175.7; IR $\left(\mathrm{KBr}, \mathrm{cm}^{-1}\right): 3320(\mathrm{~N}-\mathrm{H}), 3291(\mathrm{H}-\mathrm{C} \equiv), 1660(\mathrm{C}=\mathrm{O})$; Anal. calcd. for $\mathrm{C}_{18} \mathrm{H}_{24} \mathrm{~N}_{2} \mathrm{O}_{5}$ : C, 64.97\%; $\mathrm{H}, 6.91 \% ; \mathrm{N}$, 5.05\%; found: C 64.90\%, H 6.93\%, N 7.73\%.

1-(3,4-Dimethoxyphenyl)propane-2-yl 3-ethynyl phenylcarbamate (2). This compound $\mathbf{2}$ was synthesized from 3-ethynylaniline in a similar manner to 1 . It was later isolated and purified by using column chromatography with silica gel as solid adsorbent, and then eluted by using $3 / 2(\mathrm{v} / \mathrm{v})$ hexane/ethyl acetate to form a colorless liquid.

Yield: $30 \%$ : bp $185^{\circ} \mathrm{C} ;[\alpha]_{\mathrm{D} 20}=0^{\circ}\left(c=0.1 \mathrm{~g} / \mathrm{dL}\right.$ in $\left.\mathrm{CDCl}_{3}\right)$; ${ }^{1} \mathrm{H}$ NMR (400 MHz, $\left.\mathrm{CDCl}_{3}, \delta\right): 1.35-1.37\left(\mathrm{~d}, 3 \mathrm{H}, \mathrm{CH}_{3}\right)$, 2.66-2.92 (d, $\left.J=3.4 \mathrm{~Hz}, 2 \mathrm{H} ;-\mathrm{CH}_{2}-\mathrm{Ar}\right), 3.83(\mathrm{~d}, J=$ $\left.12.7 \mathrm{~Hz}, 6 \mathrm{H} ; \mathrm{OCH}_{3}\right), 4.05(\mathrm{~s}, 1 \mathrm{H}, \mathrm{CH}), 4.52(\mathrm{~s}, 1 \mathrm{H}, \mathrm{CH})$, 6.74-7.81 (m, 7H, Ar), $9.86(\mathrm{~s}, 1 \mathrm{H}, \mathrm{NH}) ;{ }^{13} \mathrm{C}$ NMR $(400$ $\left.\mathrm{MHz}, \mathrm{CDCl}_{3}, \delta\right): 21.1,42.9,56.1,71.6,81.4,82.3,112.5$, $121.3,121.4,112.5,121.4,122.9,126.4,127.9,128.5$, 130.0, 135.5, 147.1, 152.3, 149.9; IR $\left(\mathrm{CHCl}_{3}, \mathrm{~cm}^{-1}\right): 3322$ $(\mathrm{N}-\mathrm{H}), 3290(\mathrm{H}-\mathrm{C} \equiv), 1661(\mathrm{C}=\mathrm{O})$; Anal. calcd. for $\mathrm{C}_{20} \mathrm{H}_{21} \mathrm{NO}_{4}$ : C,70.78\%, H 6.24\%, N 4.13\%; found: $\mathrm{C}$ $70.75 \%, \mathrm{H} 6.25 \%, \mathrm{~N} 4.12 \%$.

1-(3,4-Dimethoxyphenyl)propane-2-yl 4-ethynyl phenylcarbamate (3). This compound 3 was synthesized from 4-ethynylaniline in a similar manner to 1. It was later isolated and purified by applying 
column chromatography with silica gel as solid adsorbent, and then eluted by using $3 / 2(\mathrm{v} / \mathrm{v})$ hexane/ethyl acetate to form a brown solid.

Yield: $20 \%$ : $\mathrm{mp} / \mathrm{bp} 20^{\circ} \mathrm{C}$; $[\alpha]_{\mathrm{D} 20}=0^{\circ}\left(c=0.1 \mathrm{~g} / \mathrm{dL}\right.$ in $\left.\mathrm{CDCl}_{3}\right)$; ${ }^{1} \mathrm{H}$ NMR (400 MHz, $\left.\mathrm{CDCl}_{3}, \delta\right): 1.35-1.37$ (d, $3 \mathrm{H}, \mathrm{CH}_{3}$ ), $2.66-2.92\left(\mathrm{~d}, J=3.4 \mathrm{~Hz}, 2 \mathrm{H} ;-\mathrm{CH}_{2}-\mathrm{Ar}\right), 3.83(\mathrm{~d}, J=4.9$ $\left.\mathrm{Hz}, 6 \mathrm{H} ; \mathrm{OCH}_{3}\right), 4.05$ (s, 1H, CH), $4.52(\mathrm{~s}, 1 \mathrm{H}, \mathrm{CH}), 6.74-$ 7.81 (m, 7H, Ar), 9.86 (s, 1H, NH); ${ }^{13} \mathrm{C}$ NMR $(400 \mathrm{MHz}$, $\left.\mathrm{CDCl}_{3}, \delta\right): 21.1,42.9,56.1,71.6,81.4,82.3,112.5,121.3$, $121.4,112.5,121.4,122.9,126.4,127.9,128.5,130.0,135.5$, 147.1, 152.3, 149.9; IR $\left(\mathrm{KBr}, \mathrm{cm}^{-1}\right): 3323(\mathrm{~N}-\mathrm{H}), 3290(\mathrm{H}-$ $\mathrm{C} \equiv), 1660(\mathrm{C}=\mathrm{O})$; Anal. calcd. for $\mathrm{C}_{20} \mathrm{H}_{21} \mathrm{NO}_{4}$ : C, $70.78 \%$, H 6.24\%, N 4.13\%; found: C 70.79\%, H 6.26\%, N 4.15\%.

\section{(2S)-1-(3,4-Dimethoxyphenyl)propane-2-yl 2-((prop-} 2ynyloxy)carbonylamino)propanoate (4). This compound 4 was synthesized from $(S)$-2-amino- $N$-(prop2 -ynyl)propanamide in a similar manner to 1 , in which 1 (3-dimethylaminopropyl)-3-ethyl carbodiimide hydro chloride (EDC. $\mathrm{HCl})$ was applied as a condensing agent. It was later isolated and purified by column chromatography with silica gel as solid adsorbent, and then eluted by using $3 / 2(\mathrm{v} / \mathrm{v})$ hexane/ethyl acetate to form a colorless liquid.

Yield: $25 \%: \mathrm{mp} / \mathrm{bp} 180{ }^{\circ} \mathrm{C}$; $[\alpha]_{\mathrm{D} 20}=-7.5^{\circ}(c=0.1 \mathrm{~g} / \mathrm{dL}$ in $\left.\mathrm{CDCl}_{3}\right) ;{ }^{1} \mathrm{H} \mathrm{NMR}\left(400 \mathrm{MHz}, \mathrm{CDCl}_{3}, \delta\right): 1.22-1.38(\mathrm{~m}, 6 \mathrm{H}$, $\left.\mathrm{CH}_{3}\right), 2.66-2.92\left(\mathrm{~d}, J=3.4 \mathrm{~Hz}, 2 \mathrm{H} ;-\mathrm{CH}_{2}-\mathrm{Ar}\right), 3.83(\mathrm{~d}, J$ $\left.=4.9 \mathrm{~Hz}, 6 \mathrm{H} ; \mathrm{OCH}_{3}\right), 4.05(\mathrm{~s}, 1 \mathrm{H}, \mathrm{CH}), 4.52(\mathrm{~s}, 1 \mathrm{H}, \mathrm{CH})$, 6.74-7.81 (m, 7H, Ar), $9.86(\mathrm{~s}, 1 \mathrm{H}, \mathrm{NH}) ;{ }^{13} \mathrm{C} \mathrm{NMR}(400$ $\left.\mathrm{MHz}, \mathrm{CDCl}_{3}, \delta\right): 21.1,42.9,56.1,71.6,81.4,82.3,112.5$, $121.3,121.4,112.5,121.4,122.9,126.4,127.9,128.5,130.0$, 135.5, 147.1, 152.3, 149.9; IR $\left(\mathrm{CHCl}_{3}, \mathrm{~cm}^{-1}\right): 3323(\mathrm{~N}-\mathrm{H})$, $3290(\mathrm{H}-\mathrm{C} \equiv), 1660(\mathrm{C}=\mathrm{O})$; Anal. calcd. for $\mathrm{C}_{18} \mathrm{H}_{23} \mathrm{NO}_{6}$ : $\mathrm{C}$, $61.88 \%, \mathrm{H}$ 6.64\%, N 4.01\%; found: C, $61.89 \%, \mathrm{H} 6.66 \%, \mathrm{~N}$ $4.02 \%$.

\section{Polymerization of monomers 1-4}

In this process, a monomer solution ([monomer $]=$ $0.1 \mathrm{M})$ in THF was added to (nbd) $\mathrm{Rh}^{+}\left[\eta^{6}-\mathrm{C}_{6} \mathrm{H}_{5} \mathrm{~B}^{-}\left(\mathrm{C}_{6} \mathrm{H}_{5}\right)_{3}\right]$ solution $([$ monomer $] /[\mathrm{Rh}]=50)$ under nitrogen, and it was kept at $30^{\circ} \mathrm{C}$ for $1 \mathrm{~h}$. The resulting solution was later poured into $n$-hexane $(600 \mathrm{~mL})$ to precipitate a polymer. Next, it was isolated by filtration, which was then dried under a reduced pressure to form a powder.

\section{Polymerization with the addition of menthol}

Menthol ( $1 \%$ weight) was added to the monomer solution $([$ monomer $]=0.1 \mathrm{M})$ in THF. Next, the mixture was added into (nbd) $\mathrm{Rh}^{+}\left[\eta^{6}-\mathrm{C}_{6} \mathrm{H}_{5} \mathrm{~B}^{-}\left(\mathrm{C}_{6} \mathrm{H}_{5}\right)_{3}\right]$ solution ([monomer $] /[\mathrm{Rh}]=50)$ under nitrogen atmosphere, and then kept at $30{ }^{\circ} \mathrm{C}$ for $1 \mathrm{~h}$. The produced solution was later poured into $n$-hexane $(600 \mathrm{~mL})$ to precipitate a polymer. Then, it was isolated by using the filtration process, which was followed by a drying process under reduced pressure to form a powder.

\section{Spectroscopic data of the polymers}

Poly(1). ${ }^{1} \mathrm{H}$ NMR (400 MHz, $\left.\mathrm{CDCl}_{3}, \delta\right): 1.09-1.33(\mathrm{~m}, 3 \mathrm{H}$, $\mathrm{CH}_{3}$ ), 2.53-2.92 (m, 2H, - $\left.\mathrm{CH}_{2}-\mathrm{Ar}\right), 4.24$ (s, $\left.1 \mathrm{H},-\mathrm{NHCO}-\right)$, 4.89 (s, $\left.1 \mathrm{H},-\mathrm{CH}-\mathrm{CH}_{3}\right), 6.59-6.65(\mathrm{~m}, 5 \mathrm{H},-\mathrm{CH}=\mathrm{C}, \mathrm{NH}$, $\mathrm{Ar})$; IR $\left(\mathrm{CHCl}_{3}\right): 3430(\mathrm{~N}-\mathrm{H}), 2980,2950,2650(\mathrm{C}=\mathrm{O})$, 1561.

Poly(2). ${ }^{~} \mathrm{H} \mathrm{NMR}\left(400 \mathrm{MHz}, \mathrm{CDCl}_{3}, \delta\right): 1.35-1.37$ (d, 3H, $\mathrm{CH}_{3}$ ), 2.66-2.92 (d, $J=3.4 \mathrm{~Hz}, 2 \mathrm{H} ;-\mathrm{CH}_{2}-\mathrm{Ar}$ ), 3.83 (d, $\left.6 \mathrm{H} ; \mathrm{OCH}_{3}\right), 4.05(\mathrm{~s}, 1 \mathrm{H}, \mathrm{CH}), 5.52(\mathrm{~s}, 1 \mathrm{H}, \mathrm{NH}), 6.74-7.81$ (m, 7H, Ar); IR $\left(\mathrm{CHCl}_{3}\right)$ : $3432(\mathrm{~N}-\mathrm{H}), 1733(\mathrm{C}=\mathrm{O}), 1512$. Poly(3). ${ }^{1} \mathrm{H}$ NMR (400 MHz, $\left.\mathrm{CDCl}_{3}, \delta\right): 1.35-1.37$ (d, 3H, $\left.\mathrm{CH}_{3}\right), 2.66-2.92\left(\mathrm{~d}, J=3.4 \mathrm{~Hz}, 2 \mathrm{H} ;-\mathrm{CH}_{2}-\mathrm{Ar}\right), 3.83(\mathrm{~d}$, $\left.6 \mathrm{H} ; \mathrm{OCH}_{3}\right), 4.05(\mathrm{~s}, 1 \mathrm{H}, \mathrm{CH}), 5.55(\mathrm{~s}, 1 \mathrm{H}, \mathrm{NH}), 6.74-7.81$ (m, 7H, Ar); IR $\left(\mathrm{CHCl}_{3}\right): 3431(\mathrm{~N}-\mathrm{H}), 17.33(\mathrm{C}=\mathrm{O}), 1514$. Poly(4). ${ }^{1} \mathrm{H}$ NMR (400 MHz, $\mathrm{CDCl}_{3}, \delta$ ): 1.09-1.36 (m, $6 \mathrm{H}, \mathrm{CH}_{3}$ ), 2.64-2.86 (m, 2H, $\left.-\mathrm{CH}_{2}-\mathrm{CH}-\right), 3.79$ (s, $8 \mathrm{H}$, $\left.\mathrm{OCH}_{3}, \mathrm{CH}=\mathrm{CCH}_{2}\right), 4.24$ (s, $\left.1 \mathrm{H},-\mathrm{CH}-\mathrm{NH}-\right), 4.68$ (s, $1 \mathrm{H}$, - $\left.\mathrm{CH}-\mathrm{CH}_{2}-\mathrm{Ar}\right), 5.02(\mathrm{~s}, 1 \mathrm{H},-\mathrm{NH}), 6.38(\mathrm{~s}, 1 \mathrm{H},-\mathrm{CH}=)$, 6.65-6.70 (m, 3H, Ar); IR $\left(\mathrm{CHCl}_{3}\right): 3430(\mathrm{~N}-\mathrm{H}), 1732$ $(\mathrm{C}=\mathrm{O}), 1510$.

\section{- RESULTS AND DISCUSSION}

\section{Synthesis of Monomers}

The synthetic routes for novel monomers 1-4 was displayed in Fig. 1. First, eugenol derivative was transformed into monomers 1-4 in moderate yield. In addition to elemental analysis, the monomers were identified by ${ }^{1} \mathrm{H}$ NMR and ${ }^{13} \mathrm{C}$ NMR in IR spectroscopy. Apparently, the IR spectra of all monomers showed absorbances from carbamates at $3300-3500 \mathrm{~cm}^{-1}(\mathrm{~N}-\mathrm{H})$ and $1661-1750 \mathrm{~cm}^{-1}(\mathrm{C}=\mathrm{O})$. The characteristic absorption 


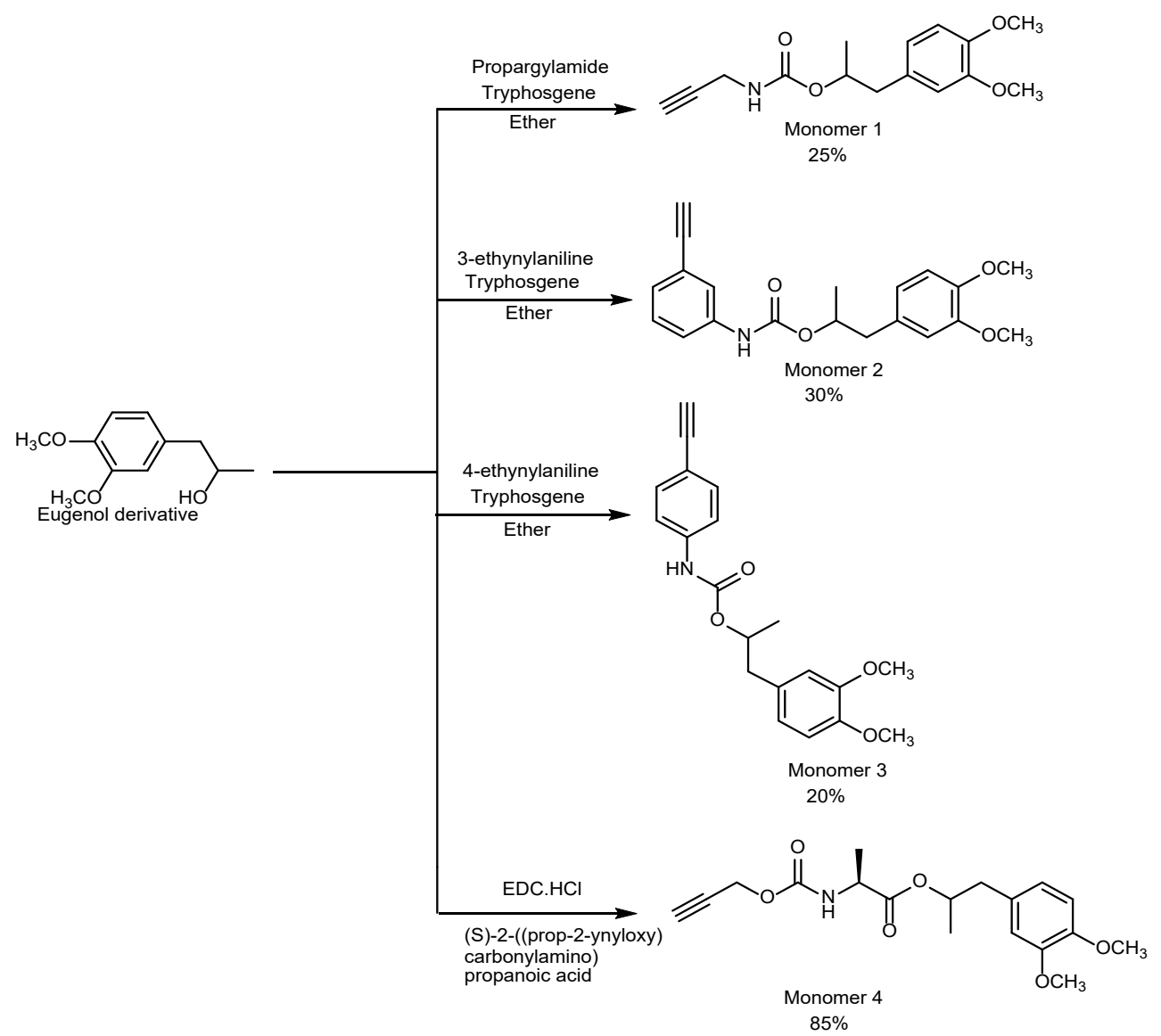

Fig 1. Synthesis of monomers 1-4

of $\mathrm{H}-\mathrm{C} \equiv$ stretched appeared at $3290 \mathrm{~cm}^{-1}$, while the absorption at $2169 \mathrm{~cm}^{-1}$ showed $\mathrm{C} \equiv \mathrm{C}$ stretching groups. Furthermore, confirmation of monomer 1-4 structures was conducted by applying ${ }^{1} \mathrm{H}$ NMR analysis. In fact, the hydrogen resonance at $2.20 \mathrm{ppm}$ showed protons from triple-bond acetylene from monomers. In addition, resonance at about 1.50 and $4.80 \mathrm{ppm}$ showed hydrogen atoms from $\mathrm{CH}_{3}$ and $\mathrm{CH}$ from eugenol derivatives. The resonance at $3.3 \mathrm{ppm}$ was experiencing splitting, which was typical for the methoxy group of eugenol derivative (Fig. 3). In addition, the ${ }^{13} \mathrm{C}$ NMR shows the present peak for $\mathrm{H}-\mathrm{C} \equiv$, and elemental analyses indicated the monomers had been successfully synthesized.

\section{Polymerization}

The polymerization of monomers 1-4 by applying (nbd) $\mathrm{Rh}^{+}\left[\eta 6-\mathrm{C}_{6} \mathrm{H}_{5} \mathrm{~B}^{-}\left(\mathrm{C}_{6} \mathrm{H}_{5}\right)_{3}\right]$ catalyst, which was particularly effective for the polymerization of monosubstituted acetylenes [12-19], gave the corresponding poly (1)-(4) in very good yields (Fig. 2). Based on FTIR analysis, the disappearance of absorption for $\mathrm{H}-\mathrm{C} \equiv$ and $\mathrm{C} \equiv \mathrm{C}$ at 3390 and $2169 \mathrm{~cm}^{-1}$, showed that triple-bonds from monomers to be completely polymerized. Moreover, the proton resonance of acetylene at $2.22 \mathrm{ppm}$ was, in fact, not visible, showing that polymerization had taken place (Fig. 3). Other polymers poly(1-3)s showed a similar spectra. Practically, polymerizations of 1-4 with the application of $\mathrm{Rh}$ catalyst gave the corresponding polymers with molecular weights ranging from $13,900-18,400 \mathrm{~g} / \mathrm{mol}$ (Table 1).

It is interesting to note that the molecular weight of poly $(1)(13,900 \mathrm{~g} / \mathrm{mol})$ could be increased by the addition of menthol (Fig. 4). As a matter of fact, this study was the first to report the addition of menthol into (nbd) $\mathrm{Rh}^{+}[\eta 6-$ $\left.\mathrm{C}_{6} \mathrm{H}_{5} \mathrm{~B}^{-}\left(\mathrm{C}_{6} \mathrm{H}_{5}\right)_{3}\right]$ catalyst to significantly increase molecular weight in high quantitative yield $(\approx 99 \%)$. Monomer 1 was observed to be in a splitting methoxy group, hence the molecular weight of the resulting polymer could be 


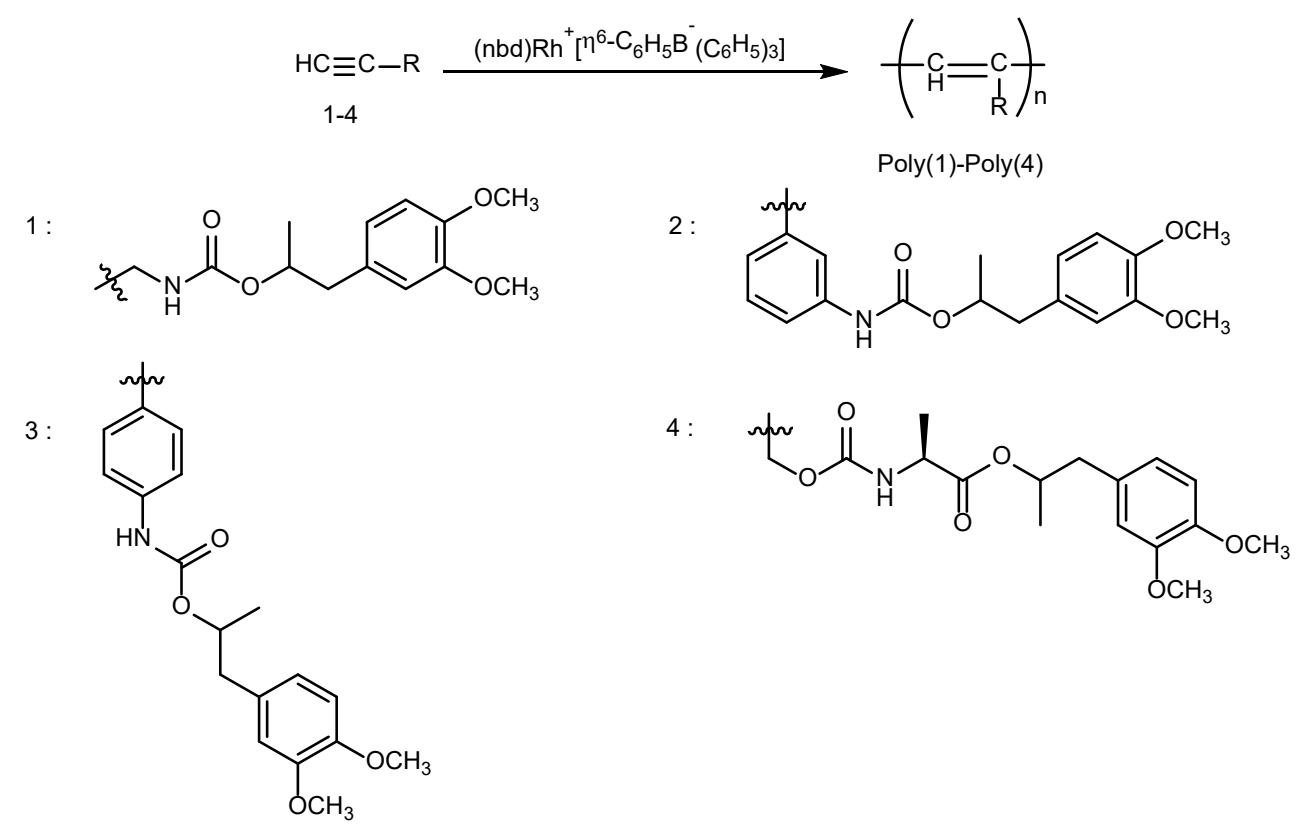

Fig 2. Synthesis of poly(1)-poly(4) using Rh catalyst

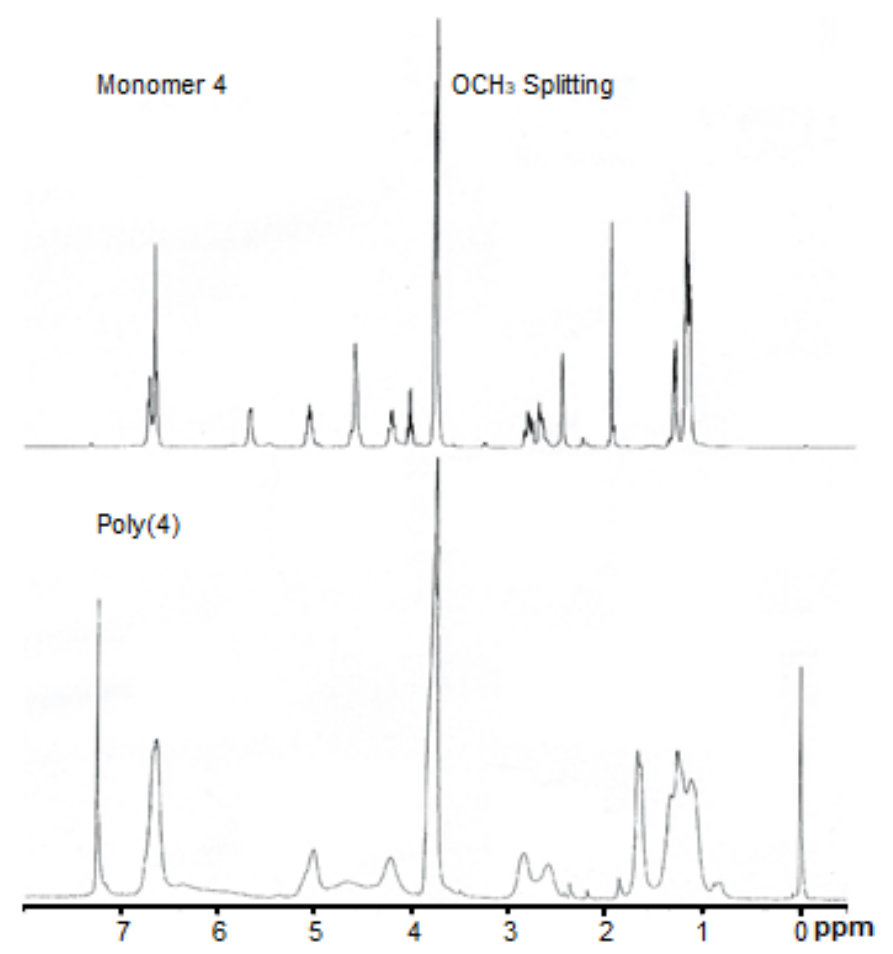

Fig 3. ${ }^{1} \mathrm{H}-\mathrm{NMR}$ spectra of monomer 4 and poly $(\mathbf{4})$

technically increased. In the work of Rahim [8], the recrystallizing monomer to produce no splitting methoxy group had been proven to increase its molecular weight and PDI significantly. Practically, the addition of menthol may induce the recrystallization of monomer $\mathbf{1}$; hence, its
Table 1. Polymerization of 1-4 with the application of $\left[(\mathrm{nbd}) \mathrm{Rh}^{+}\left[\eta^{6}-\mathrm{C}_{6} \mathrm{H}_{5} \mathrm{~B}^{-}\left(\mathrm{C}_{6} \mathrm{H}_{5}\right)_{3}\right]^{\mathrm{a}}\right.$

\begin{tabular}{lcccc}
\hline \multirow{2}{*}{ Monomer } & \multicolumn{4}{c}{ Polymer } \\
\cline { 2 - 5 } & Yield & $M_{\mathrm{n}}{ }^{\mathrm{c}}$ & $M_{\mathrm{w}} / M_{\mathrm{n}}{ }^{\mathrm{c}}$ & {$[\alpha]_{\mathrm{D}}\left({ }^{\circ}\right)^{\mathrm{d}}$} \\
\hline 1 & 99 & 13,900 & 1.6 & 0 \\
2 & 98 & 18,400 & 2.4 & 0 \\
3 & 97 & 18,200 & 2.5 & 0 \\
4 & 98 & 16,400 & 1.7 & 350 \\
\hline a) polymerization conditions $\rightarrow[\mathrm{M}]_{0}=0.1 \mathrm{M}$ in THF; $(\mathrm{nbd}) \mathrm{Rh}^{+}\left[\eta^{6}\right.$
\end{tabular}

merization conditions $\rightarrow[\mathrm{M}]_{0}=0.1 \mathrm{M}$ in THF; (nbd) $\mathrm{Rh}^{+}\left[\eta^{6}\right.$ $\left.\mathrm{C}_{6} \mathrm{H}_{5} \mathrm{~B}^{-}\left(\mathrm{C}_{6} \mathrm{H}_{5}\right)_{3}\right]=2 \mathrm{mM} ;[\mathrm{M}]_{0} /[\mathrm{Rh}]=50 ; \mathrm{T}=30^{\circ} \mathrm{C} ; \mathrm{t}=1 \mathrm{~h}$

b) $n$-hexane-insoluble part

c) determined by GPC (THF elution and polystyrene standards)

d) measured by polarimetry (concentration $=1 \mathrm{~g} / \mathrm{dL}, \mathrm{CHCl}_{3}$ )

molecular weight and PDI would significantly increase. From the technical point of view, it would be easier to synthesize the polymer, while the time required to conduct the synthesis would be faster compared to the typical method without recrystallization. In the current situation, rationales behind this finding have not been clear; hence, it requires further works.

Poly( $N$-propargylamides) and poly( $N$-propargyl carbamates) were found to be less stable, which unfortunately limited their applications [7]. In fact, applying an appropriate substituent would increase the stability of their helix. This study found that eugenol may be potentially used as the appropriate substituent. In 


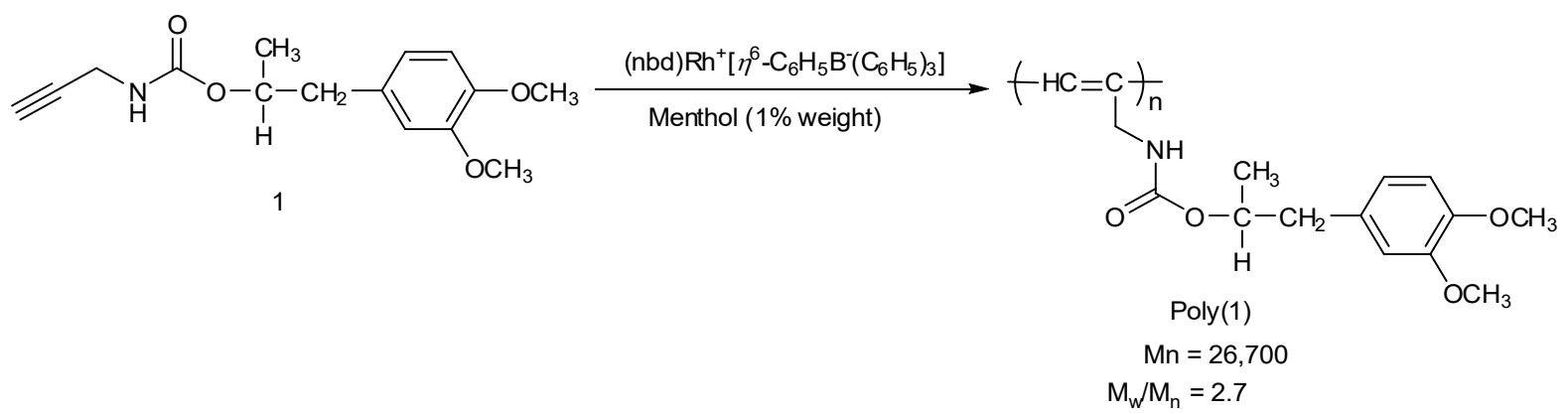

Fig 4. Synthesis of poly(1) in the presence of menthol

Table 2. Solubility of poly(1)-poly(4) in various solvent ${ }^{\mathrm{a}}$

\begin{tabular}{cccccccccc}
\hline Solvent & $\mathrm{CH}_{2} \mathrm{Cl}_{2}$ & $\mathrm{CHCl}_{3}$ & THF & Acetone & Benzene & Toluene & DMF & DMSO & Hexane \\
\hline Poly(1) & $\mathrm{O}$ & $\mathrm{O}$ & $\mathrm{O}$ & $\mathrm{O}$ & $\mathrm{O}$ & $\mathrm{O}$ & $\mathrm{O}$ & $\mathrm{O}$ & $\mathrm{x}$ \\
Poly(2) & $\mathrm{O}$ & $\mathrm{O}$ & $\mathrm{O}$ & $\mathrm{O}$ & $\mathrm{O}$ & $\mathrm{O}$ & $\mathrm{O}$ & $\mathrm{O}$ & $\mathrm{x}$ \\
Poly(3) & $\mathrm{O}$ & $\mathrm{O}$ & $\mathrm{O}$ & $\mathrm{O}$ & $\mathrm{O}$ & $\mathrm{O}$ & $\mathrm{O}$ & $\mathrm{O}$ & $\mathrm{x}$ \\
Poly(4) & $\mathrm{O}$ & $\mathrm{O}$ & $\mathrm{O}$ & $\mathrm{O}$ & $\mathrm{O}$ & $\mathrm{O}$ & $\mathrm{O}$ & $\mathrm{O}$ & $\mathrm{x}$ \\
\hline
\end{tabular}

${ }^{a \star} \mathrm{O}=$ soluble; $\mathrm{x}=$ insoluble $(3.0 \mathrm{mg}$ of polymer $/ 1 \mathrm{~mL}$ of solvent $)$

general, the helix content could be tuned by adjusting temperature [9]. In this work, poly(4) showed a large specific rotation, which was indicated by a one-handed helical structure. Meanwhile, $\operatorname{poly}(\mathbf{1}), \operatorname{poly}(2)$, and poly(3) showed no specific rotation, which indicated their helical structures to have a racemic form. In fact, poly(1)poly(3) were observed to contain eugenol moieties in a racemic form, resulting in 0 (zero) specific rotation. Meanwhile, poly(4) was revealed to contain an opticallyactive substituent (L-Alanine), and its main chain of polymer helix was stabilized by hydrogen bonding, hence resulting in a very large specific rotation $\left([\alpha]_{D}=-350^{\circ}\right)$.

\section{Solubility of Polymers}

Table 2 shows that poly(1)-poly(4) have very good solubility in various organic solvents. In other words, these polymers could completely dissolve in common solvents, including $\mathrm{CH}_{2} \mathrm{Cl}_{2}, \mathrm{CHCl}_{3}$, THF, Acetone, Benzene, Toluene, DMF, and DMSO. However, they would not be soluble in $n$-hexane.

The solubility of monosubstituted polyacetylene was, in fact, dependent on their substituent. The poor solubility of monosubstituted polyacetylene could be attributed to the rigid structure and stronger hydrogen bonding strength. As an example, poly( $N$-propargylamides) containing azobenzene and fluorene moieties was not soluble in acetone, benzene, toluene, DMF, or hexane
$[7,10]$. Thus, polyacetylenes had various drawbacks in their applications. They were particularly insoluble in solvents, making it essentially impossible to process these materials [20]. To address the problem, this study demonstrated that the introduction of the eugenol derivative scaffold might improve the polymer solubility; hence, it would be easily processed.

\section{- CONCLUSION}

Polymerization of a monomer containing carbamate and eugenol scaffolds in the presence of $\left[(\mathrm{nbd}) \mathrm{Rh}^{+}\left[\eta^{6}-\mathrm{C}_{6} \mathrm{H}_{5} \mathrm{~B}^{-}\left(\mathrm{C}_{6} \mathrm{H}_{5}\right)_{3}\right]\right.$ catalyst gave the corresponding polymers in high yields with the molecular weight ranging from 13,900-18,400 $\mathrm{g} / \mathrm{mol}$. Besides, adding menthol to the catalyst has successfully increased molecular weight of the polymers. The polymers were found to be soluble in common organic solvents and have a stable helical structure.

\section{- ACKNOWLEDGMENTS}

The author thanks the Faculty of Mathematics and Natural Science, Tadulako University, Indonesia, for their support during this research.

\section{- REFERENCES}

[1] Rahim, E.A., Sanda, F., and Masuda, T., 2004, Synthesis and properties of novel polyacetylene 
containing eugenol moieties, J. Macromol. Sci. Part A Pure Appl. Chem., 41 (2), 133-141.

[2] Rahim, E.A., Sanda, F., and Masuda, T., 2004, Synthesis and properties of novel eugenol-based polymers, Polym. Bull., 52 (2), 93-100.

[3] Miao, J.T., Yuan, L., Guan, Q., Liang, G., and Gu, A., 2017, Biobased heat resistant epoxy resin with extremely high biomass content from 2,5furandicarboxylic acid and eugenol, ACS Sustainable Chem. Eng., 5 (8), 7003-7011.

[4] Deng, J., Yang, B., Chen, C., and Liang, J., 2015, Renewable eugenol-based polymeric oil-absorbent microspheres: preparation and oil absorption ability, ACS Sustainable Chem. Eng., 3 (4), 599-605.

[5] Liu, K., Madbouly, S.A., and Kessler, M.R., 2015, Biorenewable thermosetting copolymer based on soybean oil and eugenol, Eur. Polym. J., 69, 16-28.

[6] Ohsawa, S., Sakurai, S., Nagai, K., Maeda, K., Kumaki, J., and Yashima, E., 2012, Amplification of macromolecular helicity of dynamic helical poly(phenylacetylene)s bearing non-racemic alanine pendants in dilute solution, liquid crystal and twodimensional crystal, Polym. J., 44, 42-50.

[7] Zhang, J., Ren, X., Li, S., and Huang, W., 2014, Synthesis and conformational study of novel, stable, helical poly( $N$-propargylamides) containing dipole azobenzene chromophores in the side chain, Polym. Bull., 71 (11), 2803-2818.

[8] Rahim, E.A., 2018, Unique polymerization and new smart material of eugenol-based helical polymers, Int. J. Sci. Res., 7 (11), 990-996.

[9] Shiotsuki, M., Kumazawa, S., Onishi, N., and Sanda, F., 2011, Molecular weight dependence of helical conformation of amino acid-based polyphenyl acetylenes, J. Polym. Sci., Part A: Polym. Chem., 49 (22), 4921-4925.

[10] Rahim, E.A., Sanda, F., and Masuda, T., 2006, Synthesis and properties of optically active amino acid-based polyacetylenes bearing eugenol and fluorene moieties, J. Polym. Sci., Part A: Polym. Chem., 44 (2), 810-819.

[11] Schrock, R.R., and Osborn, J.A., 1970, $\pi$-Bonded complexes of the tetraphenylborate ion with rhodium(I) and iridium(I), Inorg. Chem., 9 (10), 2339.

[12] Masuda, T., 1997, "Acetylene polymerization" in Catalysis in Precision Polymerization, Eds. Kobayashi, S., Wiley, Chichester, 67-97.

[13] Masuda, T., 1996, "Acetylenic polymer" in Polymeric Material Encyclopedia, Eds. Salamone, J.C., CRC Press, New York, 32-40.

[14] Karim, S.M.A., Nomura, R., Kajii, H., Hidayat, R., Yoshino, K., and Masuda, T., 2000, Synthesis and properties of a soluble and widely conjugated polyethylene having antryl pendant, J. Polym. Sci., Part A: Polym. Chem., 38 (S1), 4717-4723.

[15] Sone, T., Asako, R., Masuda, T., Tabata, M., Wada, T., and Sasabe, H., 2001, Polymerization of $o$ trifluoromethyl(phenylacetylene) initiated by $[\mathrm{Rh} \text { (norbornadiene) } \mathrm{Cl}]_{2}$ and $\mathrm{MoOCl}_{4}-n-\mathrm{Bu}_{4} \mathrm{Sn}$ EtOH catalysts. Formulation of order and disorder trans sequences, Macromolecules, 34 (6), 1586-1592.

[16] Shiotsuki, M., Sanda, F., and Masuda, T., 2011, Polymerization of substituted acetylenes and features of the formed polymers, Polym. Chem., 2 (5), 1044-1058.

[17] Tabata, M., Sone, T., and Sadahiro, Y., 1999, Precise synthesis of monosubstituted polyacetylenes using Rh complex catalysts. Control of solid structure and $\pi$-conjugation length, Macromol. Chem. Phys., 200 (2), 265-282.

[18] Tabata, M., Mawatari, Y., Sone, T., Yonemoto, D., Miyasaka, A., Fukushima, T., and Sadahiro, Y., 2002, Synthesis of helical substituted polyacetylenes using rhodium complex catalyst-color control through the columnar formation, Kobunshi Ronbunshu, 59 (4), 168-177.

[19] Kishimoto, Y., Itou, M., Miyatake, T., Ikariya, T., and Noyori, R., 1995, Polymerization of monosubstituted acetylenes with a zwitterionic Rhodium (I) complex, (nbd) Rh ${ }^{+}\left[\eta 6-\mathrm{C}_{6} \mathrm{H}_{5} \mathrm{~B}^{-}\left(\mathrm{C}_{6} \mathrm{H}_{5}\right)_{3}\right]$, Macromolecules, 28 (19), 6662-6666.

[20] Rahim, E.A., and Sanda, F., 2019, Synthesis and functionality of eugenol-based polyacetylenes, $\mathrm{J}$. Phys. Conf. Ser., 1242, 012003. 